\title{
Cloud Computing Research: A Review of Research Themes, Frameworks, Methods and Future Research Directions
}

\author{
Prince Kwame Senyo $^{\mathrm{a}, *}$, Erasmus Addae ${ }^{\mathrm{b}}$, Richard Boateng $^{\mathrm{a}}$ \\ ${ }^{\text {a }}$ Department of Operations and Management Information Systems, University of Ghana Business School, \\ Accra, Ghana \\ ${ }^{\mathrm{b}}$ Austin Community College, Austin, TX, USA
}

\begin{abstract}
This paper presents a meta-analysis of cloud computing research in information systems with the aim of taking stock of literature and their associated research frameworks, research methodology, geographical distribution, level of analysis as well as trends of these studies over the period of 7 years. A total of 285 articles from 67 peer review journals from the year 2009 to 2015 were used in the analysis. The findings indicate that extant cloud computing literature tends to skew towards the technological dimension to the detriment of other under researched dimensions such as business, conceptualization and application domain. Whilst there has been a constant increase in cloud computing studies over the last seven years, a significant number of these studies have not been underpinned by theoretical frameworks and models. Also, a majority of cloud computing studies utilized experiment and simulation as methods of enquiry as compared to the qualitative, quantitative, and mixed methodologies. This study contributes to cloud computing research by providing holistic insights into trends on themes, methodology, research framework, geographical focus and future research directions.
\end{abstract}

Keywords: Cloud computing, Meta-analysis, Literature review, Review, Classification 


\section{Introduction}

In recent times, the global use of computers and smartphones has increased significantly. This trend has heightened global competition and the need for businesses to expand into different geographical areas in order to be sustainable. To address this need, there is a necessity for efficient use of resources toward operational excellence. Cloud computing, an emerging innovation seeks to address these needs. Even though cloud computing is not totally new, its commercialization started around year 2000. Cloud computing simply involves the provision of information technology (IT) solutions as a service rather than as a product through the Internet (Senyo, Effah, \& Addae, 2016). According to Gartner (2016), by year 2020, more than $\$ 1$ trillion in IT expenditure will be directly or indirectly toward transition to cloud computing systems. As such there is fierce competition among major cloud service providers such as Amazon, Microsoft, Salesforce, and Google for a share in this projected revenue.

In academia, cloud computing has attracted a growing number of studies in recent years. Among these studies are some literature reviews (e.g., Bayramusta \& Nasir, 2016; El-Gazzar, 2014; Venters \& Whitley, 2012; Yang \& Tate, 2012). Although these reviews provide useful insights into cloud computing, some knowledge gaps still exist, thus the need for further reviews. These gaps are (1) limited knowledge on theories, frameworks and models that underpinned cloud computing research; (2) partial understanding of under-researched areas of cloud computing; (3) limited understanding of underpinning methodologies of cloud computing research; and (4) limited knowledge of level of analysis and geographical focus of cloud computing research. We argue that better understanding of these knowledge gaps will not only provide springboard for future studies but also enhance holistic understanding as well as contribute to the practical development of cloud computing. Thus, this paper provides a summative meta-analysis of cloud computing research from 2009 to 2015. With the aim of taking stock and providing insights into theoretical frameworks and models, research methodologies, geographical focus, and trends of cloud computing research over these years.

The rest of the paper is organized as follows. Section 2 presents a literature review of cloud computing with discussions on the general notions, delivery models and types of deployment of cloud computing. Section 3 presents the research framework that guided the classifications of literature for further analysis. In Section 4, the methodology for this study is presented whilst 
Section 5 presents findings from the review. Discussions of the findings are presented in Section 6. Section 7 concludes the paper with contributions and direction for future research.

\section{Literature Review}

The phenomenon of cloud computing has its genesis in other technologies, namely the grid, parallel and distributed systems, virtualization, multi-core chips, and Internet technologies (Buyya et al., 2009). Features that distinguish cloud computing from related technologies are on-demand self-service, broad network access, resource pooling, rapid elasticity, and measured service (Buyya, Broberg, \& Goscinski, 2011). There is still not a standard definition of cloud computing but both academics and industry players are making significant strides to bring to bear a standard definition of the technology. An attempt by Buyya et al., (2009) define cloud computing as "a parallel and distributed computing system consisting of a collection of inter-connected and virtualized computers that are dynamically provisioned and presented as one or more unified computing resources based on service-level agreements established through negotiation between the service provider and consumers." According to the United States National Institute for Standards and Technology (NIST) "cloud computing is a model for enabling ubiquitous, convenient, on-demand network access to a shared pool of configurable computing resources (e.g., networks, servers, storage, applications and services) that can be rapidly provisioned and released with minimal management effort or service provider interaction" (Mell \& Grance, 2011). In this study, cloud computing is defined as the delivery of IT infrastructure and applications as a service on-demand to individuals and organizations via Internet platforms (Senyo et al., 2016).

The types of service models that have emerged under cloud computing technology are Softwareas-a-Service (SaaS), Platform-as-a-Service (PaaS), and Infrastructure-as-a-Service (IaaS) (Zissis \& Lekkas, 2012). SaaS is a cloud computing model where applications reside on the cloud infrastructure of service providers and are delivered to users through web interfaces and programs. The main notion behind SaaS is to eliminate the practice of applications residing locally on devices of individual user as the computing powers of these individual devices cannot be leveraged to provide high computing efficiency and performance to users. Cloud computing is believed to have built its genesis from Software as a Service (Mell \& Grance, 2011).

$\mathrm{PaaS}$ is a service model which offers users a platform to build and run applications through a programming interface provided and supported by cloud service providers (Marston, Li, 
Bandyopadhyay, Zhang, \& Ghalsasi, 2011). Therefore, the issues of scalability, high server speed and storage capacities are addressed under PaaS. Hence, PaaS users can build, run, and deploy their own applications using remote IT platforms. However, users do not have absolute control over the core cloud platforms such as servers, operating systems or storage (Sultan, 2010).

Under IaaS, cloud service providers supply a range of virtual infrastructures such as virtual servers, storage and other fundamental computing resources to users which enable them deploy and run their own operating system, applications, upload or download software or files into the cloud (Mateescu, Gentzsch, \& Ribbens, 2011). Under the IaaS model, users have control over the arbitrary software and applications they have deployed into the cloud but have limited control over the virtual infrastructure provided by the cloud service provider.

The cloud service models are deployed to users through four main delivery models based on needed control, number of users, security, and privacy needs. These cloud service delivery models are public, private, hybrid and community clouds (Hsu, Ray, \& Li-Hsieh, 2014; Mouratidis, Islam, Kalloniatis, \& Gritzalis, 2013). The public cloud is where a third party owns all the physical resources and then provides cloud services to multiple users over the Internet. The users that are served by the cloud service provider ranges from individuals to corporate organizations (Mell \& Grance, 2011). Under the private cloud deployment, the cloud service is offered solely to a specific organization. The private deployment is mostly necessitated by the desire to take full control of corporate data, security guidelines and system performance. Though an organization can fully deploy its own cloud services, a third party organization can also be contracted to manage the deployment on its behalf. Additionally, the cloud services may reside off or on the premises of the organization (Zissis \& Lekkas, 2012). A community cloud deployment is where cloud services are offered to a specific group of organizations having similar mission, security requirements, policy and compliance conditions (Marston et al., 2011). The community cloud deployment is seen as a generalization of the private cloud thus, has more than one organization in the deployment. The result of a merger between different cloud deployment models such as private, public and community is termed as the hybrid cloud deployment (Mateescu et al., 2011). Although these different deployments are merged together, they remain unique on their own but are held as one through proprietary technology and standards that enable application and data operability. The hybrid cloud combines the advantages and disadvantages of private, public and community cloud 
deployment hence, is regarded as an ideal model when organizations are torn between issues of control and cost.

\section{Classification Framework}

Cloud computing is a relatively new, unique and multifaceted phenomenon hence, classification of its literature is challenging as all aspects must be taken into consideration. Therefore, the classification scheme of Yang and Tate (2012) was adapted with some modifications to reflect changes in cloud computing literature 3 years on. The scheme (see table 1) classified cloud computing into 4 top and 26 sub-themes. The 4 top themes are business issues, conceptualizing, domains and applications, as well as technology issues.

\section{[Insert Table 1 here]}

The business issues theme consolidates studies that border on business implications of cloud computing. The sub-themes under the business issues theme are cloud computing adoption, acceptance and implementation, privacy, legal and ethical issues, operational performance, trust, strategy, financial issues, and service value. The technical issues theme considers articles that pertain to the constituents, elements and mechanisms of the cloud computing technology. It mostly focuses on studies related to the technical infrastructure of cloud computing. The sub-themes under the technical issues are cloud systems performance, data center management, data management and analytics, security, architecture, service and resource management, and software development (Yang \& Tate, 2012). The conceptualization theme includes articles that provide insight into the phenomenon of cloud computing with the aim of offering better understanding (Buyya et al., 2009). As such, the conceptualizing theme is sub-divided into foundational and prediction subthemes to cater for articles that provide insight into current knowledge of cloud computing as well as future aspirations. The domains and applications theme consists of articles that are concerned with the impact of cloud computing on specific areas of society. The sub-themes include e-science, e-government, education, health, mobile computing, knowledge management, open source, as well as social media.

\section{Methodology for Review}


King and He (2006) indicate that the review of literature can be conducted in four different ways within the qualitative and quantitative domain viz. narrative, descriptive, vote counting and meta-analysis approaches. As such, this study adopted the meta-analysis technique for its review of literature. The choice of the meta-analysis approach is motivated by its ability to provide statistical support for the research being undertaken.

\section{Scope of Literature Search}

The primary source of literature for the review was electronic database searches as this practice has become apparent among information systems (IS) research (Hwang \& Thorn, 1999; Petter \& McLean, 2009). Therefore, the choice of electronic databases was deemed appropriate. The search for literature was conducted in two phases. First, a senior basket of IS journals (Association for Information Systems, 2011) were searched individually to ascertain the extent to which cloud computing research has been accorded credence in these journals. Since, this practice is evident in other studies (e.g., Duncombe \& Boateng, 2009; Ngai \& Wat, 2002; Yang \& Tate, 2012). However, it became evident that the senior basket of information systems journals did not have many studies on cloud computing. A possible reason for less research on cloud computing in these senior basket of IS journals is the relative newness and technicality of cloud computing. Second, a wider search was conducted in electronic databases such as Ebscohost, ScienceDirect, Emerald, Sage, JStor, ACM Digital Library and Google Scholar. According to Levy and Ellis (2006), these sources cover an extensive size of the top fifty information systems journals. Therefore a fair representation is assumed to be achieved.

The search was conducted with the phrase "cloud computing" and keyword "cloud" on the abstracts, keywords and titles across the databases. However, the search was limited to peerreviewed scholarly journal articles from 2009 and till 2015. The articles were subjected to manual filtering where editorials, review articles, and reports were eliminated. Because, the study set out to include only peer reviewed articles in the review. Conference papers, dissertations, books, working papers, and reviews of books were also excluded. Further checks were conducted to remove duplicates and articles from other disciplines such as computer engineering. In all, 285 articles from 67 journals were considered for classification and analysis.

Further, the final 285 articles were then classified by theme, research methodology, geographical focus, level of analysis, year of publication, publishing outlet (journal), and research framework. 
The classification by theme was based on 4 major and 26 sub-themes whilst the classification by methodology was based on qualitative, quantitative, mixed methods, simulation and experiment (Duncombe \& Boateng, 2009; Johnson \& Onwuegbuzie, 2004) and "no method". The qualitative category included articles that used qualitative research approaches and techniques. For instance, articles that used the case study as a research method and collected data through interviews and observations were classified under the qualitative group. On the other hand, articles classified under the quantitative category were those that adopted research approaches and techniques common within the positive paradigm such as survey and questionnaire.

With regards to the mixed methods group, articles in this classification adopted approaches and techniques of both the qualitative and quantitative methods. Simulations and experimental studies are those that adopted techniques that seek to imitate the real world operation or test a new idea through a computer program. However, studies that were conducted without a research methodology were considered for the "no method" group. In relation to geographical focus, articles were classified based on the continent where the study is focused or data was collected. The categories under this classification were Africa, Asia, Australia, Europe, North America, South America, Cross-continent and Global. The cross-continent category included articles that were conducted in relation to two or more continents whilst the global category included articles that do not have a specific geographical target and therefore were location independent.

The level of analysis classification considers the stage at which the study was conducted and the targeted group. Level of analysis classification in information systems research can be at three levels, namely micro, meso and macro. The micro level studies pertain to individual whilst meso is based on organizations and industries. Macro studies are based on a country or/and association of countries for example studies on West African countries or the European Union. This study also classified the final 285 papers based on the journals in which the studies were published. The final classification considered under this study is the research frameworks adopted by extant cloud computing research. Several research frameworks were revealed during the classification but some studies did not use a definite research framework hence, were classified under the "no theory" group.

\section{Presentation of Findings}

\section{Publication Outlets}


The full list of journals and their respective articles are presented in Appendix 1. The distribution of journals with substantial number of studies is as follows. The Journal of Cloud Computing recorded the highest number of studies (31\%). This situation was not surprising as the journal is dedicated to the area of cloud computing research. The Future Generation Computer Systems was the second highest journal (12\%) followed by the International Journal of Information Management (7\%). The rest are the Computer Law \& Security Review (6\%), Expert Systems with Applications (4\%), Information Sciences (3\%), Information Systems (3\%), Decision Support Systems (3\%), Business \& Information Systems Engineering (2\%), and Journal of Enterprise Information Management (2\%). Computers in Industry, European Journal of Information Systems, International Journal of Accounting Information, Advances in Engineering Software, Communications of the Association for Information Systems, Computer Standards \& Interfaces, Electronic Commerce Research and Applications, International Journal of Cloud Computing and Services Science, Journal of Information Technology, Journal of Management Information Systems, Journal of Network and Computer Applications, Journal of Systems and Information Technology, The Electronic Journal on, Information Systems in Developing Countries and The Electronic Library journals all recorded 1\%.

\section{Research Themes}

The representation of articles categorized under cloud computing research themes are as follows. The technological issues theme recorded (47.4\%), business issues (31.9\%), domain and application (11.9\%), as well as cloud computing conceptualizing (8.8\%). Given that cloud computing is driven by technical technologies such as servers, networks, application and so on, it was not surprising that the technical issues theme had the greater share of literature. The dominance of the technical issues theme also shows that less attention has been paid to other themes such as cloud computing business issues, conceptualization, and application domains. Figure 1 shows the distribution of articles under the respective research themes.

\section{[Insert Figure 1 here]}

Years of Publication 
The classification by year of publication showed a growing trend of articles published in relation to cloud computing. Figure 2 shows distribution of articles by year of publication. The year 2009 recorded 6 articles whilst the subsequent years recorded a rise in the number of articles published progressively. The year 2010 saw 12 articles published, followed by 2011 with 26 articles, then 2012 with 46 articles and 2013 with 67 articles. The year 2014 and 2015 recorded 65 and 63 articles respectively. Considering the increasing number of articles over the years, we can predict that literature on cloud computing will continue on the increase.

\section{[Insert Figure 2 here]}

\section{Research Methodology}

In relation to the research methodologies utilized in the literature reviewed, studies that are technical in nature and more of simulations and experiments recorded the highest count of 59.3\%, followed by "no method" studies $14.7 \%$ and then quantitative method $13 \%$. The remainders are qualitative $11.6 \%$ and mixed methods $2.5 \%$. Studies categorized under the "no method" group are those that did not utilize a definite methodological approach. Figure 3 shows distribution of articles per research methodologies utilized.

\section{[Insert Figure 3 here]}

\section{Level of Analysis}

The findings (see Figure 4) in this sub-section pertain to the level at which the studies reviewed were conducted. It was however not surprising that, majority of the articles were in the general category $(66.7 \%)$ as most of these articles are technical in nature. As such these articles do not

pertain to an individual, organization or country since; they mostly seek to provide a general body of knowledge applicable at all levels relating to cloud computing. In contrast, studies under the meso category $(21.4 \%)$ of analysis pertain to organizations. The meso category is followed by micro $(8.0 \%)$ and lastly the macro $(3.9 \%)$.

\section{[Insert Figure 4 here]}




\section{Geographical Focus}

As a large chunk of studies did not target organizations, individuals or countries, it is also not surprising to see the geographical focus of the reviewed articles largely dominated by global category. Articles in the global category are those that do not focus on specific country or continent thus, are generic articles that are not geographically focused. The distribution of the articles are as follows, Global 71.2\%, Europe 8.4\%, Asia 7.4\%, Australia 4.2\%, Africa 3.1\%, North America 2.8\%, Cross-continent $2.5 \%$ and South America $0.4 \%$. Studies that cover countries in two or more continents were categorized in the cross-continent group. The distribution of articles is shown in Figure 5 .

\section{[Insert Figure 5 here]}

\section{Research Frameworks}

This categorization was carried out based on research framework or models used in the articles reviewed. It was evident that most of the studies did not use frameworks (e.g., Mauch, Kunze, \& Hillenbrand, 2013; Sithole et al., 2013; Varadi, Kertesz, \& Parkin, 2012). Given that a large number of the articles reviewed utilized simulation and experiments, they were not based on any research framework. However, frameworks used by in some of the articles reviewed include the Technology Adoption Model (TAM), Diffusion of Innovation (DOI), Resource Based-View (RBV), Grounded Theory, Migration Theory, Theory of Reasoned Action (TRA), and Technology Organization and Environment framework (TOE). Among the articles that utilized research frameworks, the TOE framework recorded 5.26\%, whilst TAM and RBV had $1.40 \%$. Some studies also combined two frameworks in their investigation. Table 2 shows the distribution of articles and their respective research frameworks.

\section{[Insert Table 2 here]}




\section{DISCUSSION}

This section presents discussions on findings presented in Section 5 of this study. The discussion covers publication outlets, research themes, year of publication, research methodology, level of analysis, geographical focus, as well as research frameworks and models.

\section{Publication Outlets}

Cloud computing by its nature cuts across several disciplines, namely information systems, computer science, computer engineering, finance, accounting, and so on. Thus literature on cloud computing can be found across journals in these areas. Within the information systems discipline, cloud computing has witnessed a relative growing amount of research. However, aside a few leading journals such as International Journal of Information Management (e.g., Cegielski, JonesFarmer, Wu, \& Hazen, 2012; Garrison, Wakefield, \& Kim, 2015; Jones, 2015; Lian, 2015; Rasheed, 2014; Sultan, 2010, 2013, 2014), Future Generation Computer Systems (e.g., Garg, Versteeg, \& Buyya, 2012; Mateescu et al., 2011; Pandey, Voorsluys, Niu, Khandoker, \& Buyya, 2012; Thilakanathan, Chen, Nepal, Calvo, \& Alem, 2014; Yu, Niu, Yang, Mu, \& Susilo, 2014; Zissis \& Lekkas, 2012), Computer Law and Security Review (e.g.,Gray, 2013; Joint \& Baker, 2011; Ryan \& Falvey, 2012; Varadi et al., 2012), Expert Systems with Applications (e.g.,García Coria, Castellanos-Garzón, \& Corchado, 2014; Luo, Li, \& Chen, 2014; Navimipour, 2015; Rezaei, Chiew, Lee, \& Shams Aliee, 2014) and Decision Support Systems (Benlian \& Hess, 2011; Jianhui Huang, Kauffman, \& Ma, 2015; Laatikainen, Mazhelis, \& Tyrväinen, 2014; Marston et al., 2011; Wang et al., 2016); cloud computing literature seems not be accorded the necessary credence in the senior basket of information systems journals. A likely explanation of this trend is a newest of cloud computing as a research area. However, by the continuous increase in cloud computing related publications, we believe that more publication on cloud will be witnessed in the coming years in other leading information systems journals.

\section{Research Themes}

Research themes analyzed under cloud computing literature are business and technological issues, cloud computing conceptualization as well as cloud computing application domains. The 
business issues theme considers research related to the socio-technical aspect of cloud computing such as adoption, cost, privacy, legislation, and ethics. Most studies within the business issues theme focused more on cloud computing adoption, specifically factors that influence the adoption of cloud computing. These adoption studies (e.g., Alshamaila, Papagiannidis, \& Li, 2013; Cegielski, Jones-Farmer, Wu, \& Hazen, 2012; Lian, 2015; Lian, Yen, \& Wang, 2014) mainly investigate organizational adoption of cloud computing whilst less attention is paid to individual and country level adoption. The central idea among the adoption studies is to determine the factors that will favor or disfavor adoption. This is as a result of fewer consensuses in literature about cloud computing adoption factors. Factors identified as enablers include top management support, compatibility, relative advantage, firm size, technology readiness and competitive pressure (Dahiru et al., 2014; Lian, 2015; Lian et al., 2014; Nkhoma \& Dang, 2013; Safari, Safari, \& Hasanzadeh, 2015). On the other hand, factors considered as constraining cloud computing adoption include cloud security, privacy, lack of legislation, as well as technical infrastructure in some developing countries (Low, Chen, \& Wu, 2011; Wei et al., 2014).

Also some studies (e.g., Huang \& Nicol, 2013; Ryan \& Falvey, 2012) within the business issues theme also focused on trust and privacy. The major concern in these studies is how to curtail trust challenges that might arise as a result of cloud computing adoption. To address this concern of trust and privacy, legislations are proposed as measures to protect cloud users (Gray, 2013). It is argued that the availability of legislations will allay fear and decrease security concerns about the cloud innovation. The debate about ethics has received less research attention; however concerns have been raised (Ratten, 2014) about how to ensure confidentiality. Given that vital corporate data is store in the cloud, studies related to ethical issues have called for measures to curtail issues of data confidentiality. On cost, studies within this sub-theme (e.g., Byun, Kee, Kim, \& Maeng, 2011; Laatikainen et al., 2014; Mtebe \& Raisamo, 2014) support the argument that cloud computing has lowered technology startup cost. However, the issue of long term cost has been identified as concern that needs clarification. In addition, apprehensions have also been expressed about the transparency in the billing of cloud computing services. As such, calls have been made for more transparency in the billing of cloud services (Yeo, Venugopal, Chu, \& Buyya, 2010). Studies on legislation seek to provide ways by which cloud computing can be supported with the right laws (Varadi et al., 2012) in order to increase confidence of the adopter. Some studies (e.g., Gray, 2013; Joint \& Baker, 2011) allude to the non-existence of universal laws as one challenge 
facing cloud computing as it defies geographical boundaries. Thus the issue of jurisdiction is identified as a major challenge hindering cloud computing development especially in developing countries where laws are always playing catchup with technology (Senyo et al., 2016).

Contrary to the business issue theme, studies within the technological issues theme take a different trajectory. The focus of these studies is on core infrastructure that supports cloud computing. Issues examined under the technological issues theme include cloud computing performance, data management, data center management, service management, architecture and security. Cloud computing performance studies (e.g., Mauch, Kunze, \& Hillenbrand, 2013; Sithole et al., 2013) argue for the development of cloud-based infrastructure that will support the increasing number of users and variety of cloud-based applications. These studies also point out that the performance of cloud-based systems still needs further improvement due to the emergence of big data with its associated volume and speed of data. However, computing performance under cloud computing has been identified to have improved significantly in recent time. Thus, cloud computing is seen as vital in the quest to increase computing performance.

Studies (e.g., Grolinger, Higashino, Tiwari, \& Capretz, 2013; Varadi et al., 2012) related to data management under the technological issues identify innovations such as Hadoop, high performance computing, and distribution computing as enablers for optimizing cloud computing data. In addition, these studies acknowledge cloud computing as an enabler of green IT which consolidates IT resources towards saving more energy and reducing carbon emission. However, one key issue not discussed under data center management is the case of developing countries where there is limited internet infrastructure, skilled professional and electricity to manage and support cloud computing. Thus data center location is seen as a key issue that needs further research.

Cloud service management studies discussed the various services that are provided through the cloud computing infrastructure. These cloud computing services fall within the domain of SaaS, PaaS and IaaS (Buyya et al., 2009). Some of the services include salesforce's CRM and ERP, Amazon's web services, Microsoft's dynamics and office 365, Dropbox as well as Google's docs. However, studies within the service management sub-theme (e.g., Garg, Versteeg, \& Buyya, 2012; Giessmann \& Stanoevska-Slabeva, 2013; Walterbusch, Martens, \& Teuteberg, 2013) turn to focus more on SaaS and PaaS compare to IaaS services. In the same vein, some studies also focus on computing technologies that have been built on cloud computing infrastructure. These studies 
(e.g., Mauch et al., 2013; Zhang, Li, \& Zheng, 2013) argue that virtualization technology forms the underlying foundation for cloud computing technologies. As such, features such as application portability, resource sharing and aggregation of cloud computing technologies are enabled by virtualization. The key issues discussed among cloud computing technologies studies are the challenges currently facing them such as standardization, data protection, user confidence and most importantly cloud security. Thus, cloud service providers are pointed to address these issues to enable increased adoption.

The nature of cloud computing makes its adoption a dilemma. The prevalent concern of cloud computing is security. Even though cloud service providers have provided assurances, the issue of security remains a major concern among adopters and potential adopters. Studies (e.g., Svantesson, 2012; Yu, Niu, Yang, Mu, \& Susilo, 2014; Zissis \& Lekkas, 2012) point out factors that pose cloud security challenges and also provide pointers on how to address some of the challenges. Cloud security challenges identified include system availability, data lost, data confidentiality and privacy as well as lack of data audit. To mitigate cloud security challenges, these studies point to the adoption of private cloud as opposed to public. However, the ideal cloud deployment model, according to Khorshed, Ali, \& Wasimi (2012) is the hybrid cloud. Thus, recommendation is made for organizations to keep sensitive cloud services on private clouds whilst services consider less sensitive on public cloud. However, a challenge is made to cloud service providers to put measures in place to reassure adopters as well as increase education about cloud security. Again, literature has acknowledged the need for efforts toward providing strong security for cloud systems.

Another theme examined under the research theme is cloud computing conceptualizing. This theme comprises articles (e.g., Armbrust et al., 2010; Buyya et al., 2009; Venters \& Whitley, 2012; Yang \& Tate, 2012) that seek to provide a foundation for cloud computing. Given that cloud computing is relatively new in academia; it has become important to clearly explain key terminologies, processes, constructs, service, and delivery models. This theme views cloud computing research from two main lenses - foundational and predictive. The foundation articles seek to provide understanding of the building blocks of cloud computing. Understanding the basis of cloud computing will provide support towards its growth. Thus, studies within the foundational sub-theme strive to accomplish this task. For example, Buyya et al. (2009) as part of conceptualizing cloud computing provides working definitions of cloud computing, meaning of services delivery models and types of cloud services. It is argued that understanding this aspect 
will support the interest and propensity of adoption. Some studies (e.g., Marston et al., 2011; Son, Lee, Lee, \& Chang, 2014; Wang et al., 2016) under the conceptualization have also made some prediction of future breakthroughs of cloud computing. The main argument under the prediction sub-theme is that cloud computing will permeate most aspects of individual and organizational settings given the benefits that accrue from cloud computing. The prediction sub-theme provides insight into future systems that will leverage cloud computing in untapped areas such as health (Sultan, 2014) and high-performance computing (Mauch et al., 2013).

The final theme concerns the domain and areas in which cloud computing has been applied. The articles in this theme investigate the application of cloud computing in areas such as education (Le Roux \& Evans, 2011; Sultan, 2010), e-Science (Pi et al., 2011), e-Government (Decman \& Vintar, 2013; Zissis \& Lekkas, 2012), green IT (Basmadjian, Meer, Lent, \& Giuliani, 2012; Gottschalk \& Kirn, 2013), mobile cloud computing (Fernando, Loke, \& Rahayu, 2013; Thilakanathan et al., 2014) and knowledge management (Lai, Tam, \& Chan, 2012; Sultan, 2013). The studies acknowledge the positive transformation cloud computing has brought to these domains. As such, these studies advocate for development of more cloud-based applications to support operations in these area. They believe current benefits enjoyed from cloud computing in these domains could be increased through development of new applications. The studies challenge service providers to consider other non-IT related domains such as agriculture, transportation and mining for cloud computing application.

\section{Years of Publication}

Cloud computing research started to gain recognition around 2009 and has seen considerable rise over the years. From 6 journal articles in year 2009, cloud computing research continues to rise yearly as there are over 200 journal articles currently. We predict that more studies will be conducted on cloud computing in the coming years. This position is supported by the increased global use of cloud computing technologies. The main enabler for cloud computing is the Internet. Reduced Internet cost and availability in most parts of the world will lead to more interest and ultimate use of cloud computing. However, more research is needed to create awareness and also fix issues of concern such as security, trust, and privacy. Thus, we call for more studies on cloud computing from the socio-technical perspective as many adopters of cloud computing will rely more on non-technical issues when considering cloud computing adoption. 


\section{Research Methodology}

Given that cloud computing research is fairly new to information systems, much of the studies did not use well established research methodologies. It was observed that a limited number of research methodologies were used in the studies reviewed. Out of 285 articles reviewed, only 116 studies used either qualitative (e.g., Alshamaila et al., 2013; Jones, 2015; Mital, Pani, Damodaran, \& Ramesh, 2015), quantitative (Oliveira, Thomas, \& Espadanal, 2014; Park \& Ryoo, 2013; Ratten, 2014) and mixed research methodologies. Majority of articles in this review were technical in nature and utilized simulation (e.g., Garg et al., 2012; Giessmann \& Stanoevska-Slabeva, 2013; Grolinger et al., 2013; Hu \& Tang, 2015; Mauch et al., 2013; Sithole et al., 2013) as methods of enquiry. Also, some studies (e.g., Buyya et al., 2009; Marston et al., 2011; Sultan, 2013) did not utilize any research methodology. One possible explanation of why most studies are not underpinned by research methodology could be the relative newness of cloud computing as a research area. Given that extant cloud computing reviews (e.g., Bayramusta \& Nasir, 2016; Venters \& Whitley, 2012; Yang \& Tate, 2012) have not considered methodologies utilized in cloud computing research, this study provides insight into what future cloud computing research may focus on in terms of methodology in order to add more rigour to their studies.

\section{Level of Analysis}

The level of analysis categorization considers the focus of cloud computing research in terms of individual, organizational, national and global perspectives. The majority of the articles reviewed were in the general category. Articles in this category do not have specific research focus thus, they seek to provide general understanding of cloud computing. However, apart from the articles that had general focus, a significant number of studies on cloud computing also focused on the organizational level compared to individual and national level studies. This point to the fact that information systems is still recognized to be important in organizations. Despite this acknowledgement, we believe research on cloud computing at the macro level (national level) will create more awareness and support towards favorable policies for cloud computing. Again, national and global level research may provide valuable insights that will foster worldwide legislation towards ease of adoption as well as use of cloud computing. Thus, we call for more research on cloud computing at the national and global levels. In extant cloud computing reviews 
(e.g., Bayramusta \& Nasir, 2016; Venters \& Whitley, 2012; Yang \& Tate, 2012) limited understanding has been provided on the level of analysis classification, as such we consider this extraction an important contribution to cloud computing research.

\section{Geographical Focus}

This category examines cloud computing research from the geographical focus. We examine the geographical regions used as sources for data for the articles reviewed. As such, extant cloud computing literature was classified based on continents, cross continent as well as global studies. The findings reveal that most of the studies did not use specific geographical location as data source. Thus, these studies were classified under the global context. Aside this classification, the distribution of articles by continent revealed that significant amount of studies on cloud computing are conducted from the context of Asia, Europe, Africa and North America, as well as a cross continent. Studies conducted in the Asia region relates to countries like Taiwan, China, Korea and India (e.g., Lai et al., 2012; Lian et al., 2014; Park \& Ryoo, 2013). Whereas studies related to Europe, are from United Kingdom, Norway, Germany, Finland and the European Union at large (e.g., Alshamaila et al., 2013; Benlian \& Hess, 2011; Jones, 2015). In Africa, countries with representation were South Africa, Botswana, Kenya, Nigeria and Sub-Sahara regional block of countries (e.g., Dahiru et al., 2014; Le Roux \& Evans, 2011; Makena, 2013). Cross continent studies focused on the United States and United Kingdom, Turkey and the United States (e.g., Ratten, 2015), as well as India and United States (e.g., Ratten, 2014). As extant cloud computing literature has focused mainly on developed countries, it is therefore important for more studies from developing countries in order to address contextual and social idiosyncratic issues within these two contexts. Also, we view cloud computing as a platform toward closing the digital divide between developing counties and developed countries. Thus, we call for more studies from developing countries so that the gap in the digital divide can be reduced if not removed completely.

\section{Research Frameworks}

Some prominent research frameworks and models were used in extant cloud computing studies. Among the frameworks and model are the TAM (Gottschalk \& Kirn, 2013; Ratten, 2015; Wu, 2011), DOI (Oliveira et al., 2014), Grounded Theory (Dahiru et al., 2014), Migration Theory (Bhattacherjee \& Park, 2014), TRA (Benlian \& Hess, 2011), TOE (Hsu et al., 2014; Lian, 2015; 
Lian et al., 2014; Low et al., 2011), Social Cognitive Theory (Ratten, 2014) as well as the TwoFactor Theory (Park \& Ryoo, 2013). From the literature reviewed, it was observed that two groups of frameworks and models were used in cloud computing research. The first group transcends the individual level (micro level) whilst the second group of frameworks focused on the organizational level (meso level). As extant cloud computing has focused mainly on individual and organizational levels, we suggest that cloud computing research should consider investigations on the national level. By this we believed more awareness will be created toward use and adoption of cloud computing. Also, we believe national level research will provide the necessary knowledge to drive positive policy direction and legislation on cloud computing.

Another observation is that studies that were underpinned by theoretical frameworks or models turn to combine theories. For instance Oliveira et al., (2014) combined the DOI and TOE frameworks in investigating the determinants of cloud computing adoption in the manufacturing and services sectors. In another instance, in investigating ethical issues related cloud computing adoption in India and US, Ratten (2014) combined the TAM and the social cognitive theory. In as much as some theories were used, most research on cloud computing were not theoretically directed. As such, we argue that largely most extant cloud computing research utilized little or in some cases no theoretical frameworks or models. We therefore posit that for cloud computing research to gain prominence in leading information system research, new studies can utilize well established research frameworks and models. The research frameworks and models utilized in extant cloud computing literature are presented in Table 3. The table shows the frameworks and models, the level application and their respective studies.

\section{[Insert Table 3 here]}

\section{Conclusion}

This study examines pertinent cloud computing literature through a meta-analysis of 285 articles from 67 information systems related journals to determine current stock of cloud computing literature, conceptual approaches, research methodology, geographical distribution, and the trend of studies over the years to indicate knowledge gaps yet to be addressed. The findings point out that issues pertaining to the technical theme have witnessed more research than the business issues, conceptualization and application domains. Thus, we call more for studies on cloud computing 
from the socio-technical perspective in order to cater for sub-themes such as legislation, trust, ethics and cost within the business issues theme. Further, future studies under the business theme should consolidate the adoption factors so that a clear direction can be provided for research and practice.

In relation to the methodological approaches utilized in extant cloud computing literature, it was revealed that research over the years purport not to make use of overt research methodologies. As such, a substantial amount of cloud computing literature failed to utilize established research methodologies such as quantitative, qualitative and mixed methods. On the brighter side, extant research on cloud computing continues to rise over the years. Thus, calls are made for the utilization of well-established research methodologies in future studies. It was also revealed that there is a gap in the geographical distribution of cloud computing literature as developed regions such as Europe and some parts of Asia seems to have more research than the developing regions such as Africa and some parts of South America. It was also observed that extant cloud computing literature has failed to utilize research frameworks. The large volume of cloud computing research in the technical theme is the contributing factor to this trend. Therefore, there is a need for studies that are situated within solid research frameworks, models or theories. It is important to establish that this study may fall short of some literature since only peer reviewed articles were considered in this review.

This study also makes the following contributions. First, it provides a holistic view on cloud computing research over the years. This knowledge has pointed out areas that need more research efforts such as use of frameworks, and methodologies. Second, this study provides insights into application domains that have utilized cloud computing and those that are yet too. As such practitioners in these domains can use this knowledge to redesign their business processes in order to take advantage of cloud computing. Lastly, this study provides the foundation toward a better understanding of the area of cloud computing as well as future research efforts.

\section{References}

Alshamaila, Y., Papagiannidis, S., \& Li, F. (2013). Cloud computing adoption by SMEs in the north east of England: A multi-perspective framework. Journal of Enterprise Information Management, 26(3), 250-275. https://doi.org/10.1108/17410391311325225

Armbrust, M., Stoica, I., Zaharia, M., Fox, A., Griffith, R., Joseph, A. D., ... Rabkin, A. (2010). A view of cloud computing. Communications of the ACM, 53(4), 50. https://doi.org/10.1145/1721654.1721672 
Association for Information Systems. (2011). Senior Scholars' Basket of Journals. Retrieved 10 June 2016, from https://aisnet.org/?SeniorScholarBasket

Basmadjian, R., Meer, H., Lent, R., \& Giuliani, G. (2012). Cloud computing and its interest in saving energy: the use case of a private cloud. Journal of Cloud Computing: Advances, Systems and Applications, 1(5), 1-25. https://doi.org/10.1186/2192-113X-1-5

Bayramusta, M., \& Nasir, V. A. (2016). A fad or future of IT?: A comprehensive literature review on the cloud computing research. International Journal of Information Management, 36(4), 635-644. https://doi.org/10.1016/j.ijinfomgt.2016.04.006

Benlian, A., \& Hess, T. (2011). Opportunities and risks of software-as-a-service: Findings from a survey of IT executives. Decision Support Systems, 52(1), 232-246. https://doi.org/10.1016/j.dss.2011.07.007

Bhattacherjee, A., \& Park, S. C. (2014). Why end-users move to the cloud: a migration-theoretic analysis. European Journal of Information Systems, 23(3), 357-372. https://doi.org/10.1057/ejis.2013.1

Buyya, R., Broberg, J., \& Goscinski, A. (2011). Cloud Computing: Principles and Paradigms. Cloud Computing: Principles and Paradigms. New Jersey: John Wiley \& Sons, Inc. https://doi.org/10.1002/9780470940105

Buyya, R., Buyya, R., Yeo, C. S., Yeo, C. S., Venugopal, S., Venugopal, S., ... Brandic, I. (2009). Cloud computing and emerging IT platforms: Vision, hype, and reality for delivering computing as the 5th utility. Future Generation Computer Systems, 25, 599-616. https://doi.org/10.1016/j.future.2008.12.001

Byun, E. K., Kee, Y. S., Kim, J. S., \& Maeng, S. (2011). Cost optimized provisioning of elastic resources for application workflows. Future Generation Computer Systems, 27(8), 10111026. https://doi.org/10.1016/j.future.2011.05.001

Cegielski, C. G., Jones-Farmer, L. A., Wu, Y., \& Hazen, B. T. (2012). Adoption of cloud computing technologies in supply chains: An organizational information processing theory approach. International Journal of Logistics Management, 23(2), 184-211. https://doi.org/10.1108/09574091211265350

Dahiru, A. A., Bass, J. M., Allison, I., Abubakar, A. D., Bass, J. M., Allison, I., ... Allison, I. (2014). Cloud computing: Adoption issues for sub-saharan African SMEs. The Electronic Journal of Information Systems in Developing Countries, 62(1), 1-16.

Decman, M., \& Vintar, M. (2013). A possible solution for digital preservation of e-government: A centralised repository within a cloud computing framework. Aslib Proceedings, 65(4), 406-424. https://doi.org/10.1108/Ap-05-2012-0049

Duncombe, R., \& Boateng, R. (2009). Mobile Phones and Financial Services in Developing Countries: a review of concepts, methods, issues, evidence and future research directions. Third World Quarterly, 30(7), 1237-1258. https://doi.org/10.1080/01436590903134882

El-Gazzar, R. F. (2014). A Literature Review on Cloud Computing Adoption Issues in Enterprises. In Creating Value for All Through IT (Vol. 429, pp. 214-242). Aalborg, Denmark: Springer. https://doi.org/10.1007/978-3-662-43459-8_14

Fernando, N., Loke, S. W., \& Rahayu, W. (2013). Mobile cloud computing: A survey. Future Generation Computer Systems. https://doi.org/10.1016/j.future.2012.05.023

García Coria, J. A., Castellanos-Garzón, J. A., \& Corchado, J. M. (2014). Intelligent business processes composition based on multi-agent systems. Expert Systems with Applications, 41(4 PART 1), 1189-1205. https://doi.org/10.1016/j.eswa.2013.08.003

Garg, S. K., Versteeg, S., \& Buyya, R. (2013). A framework for ranking of cloud computing services. Future Generation Computer Systems, 29(4), 1012-1023. 
https://doi.org/10.1016/j.future.2012.06.006

Garrison, G., Wakefield, R. L., \& Kim, S. (2015). The effects of IT capabilities and delivery model on cloud computing success and firm performance for cloud supported processes and operations. International Journal of Information Management, 35(4), 377-393. https://doi.org/10.1016/j.ijinfomgt.2015.03.001

Gartner. (2016). Gartner Says by 2020 'Cloud Shift' Will Affect More Than $\$ 1$ Trillion in IT Spending. Retrieved 1 August 2016, from http://www.gartner.com/newsroom/id/3384720

Giessmann, A., \& Stanoevska-Slabeva, K. (2013). Business Models of Platform as a Service (PaaS) Providers: Current State and Future Directions. Journal of Information Technology Theory and Application, 13(4), 31-55.

Gottschalk, I., \& Kirn, S. (2013). Cloud computing as a tool for enhancing ecological goals?: Analyzing necessary preconditions on the consumer side. Business and Information Systems Engineering, 5(5), 299-313. https://doi.org/10.1007/s12599-013-0284-2

Gray, A. (2013). Conflict of laws and the cloud. Computer Law and Security Review, 29(1), 5865. https://doi.org/10.1016/j.clsr.2012.11.004

Grolinger, K., Higashino, W. a, Tiwari, A., \& Capretz, M. A. (2013). Data management in cloud environments: NoSQL and NewSQL data stores. Journal of Cloud Computing: Advances, Systems and Applications, 2, 22. https://doi.org/10.1186/2192-113X-2-22

Hsu, P. F., Ray, S., \& Li-Hsieh, Y. Y. (2014). Examining cloud computing adoption intention, pricing mechanism, and deployment model. International Journal of Information Management, 34(4), 474-488. https://doi.org/10.1016/j.ijinfomgt.2014.04.006

$\mathrm{Hu}, \mathrm{X} ., \mathrm{\&}$ Tang, C. (2015). Secure outsourced computation of the characteristic polynomial and eigenvalues of matrix. Journal of Cloud Computing, 4(1), 1-6. https://doi.org/10.1186/s13677-015-0033-9

Huang, J., Kauffman, R. J., \& Ma, D. (2015). Pricing strategy for cloud computing: A damaged services perspective. Decision Support Systems, 78, 80-92. https://doi.org/10.1016/j.dss.2014.11.001

Huang, J., \& Nicol, D. M. (2013). Trust mechanisms for cloud computing. Journal of Cloud Computing: Advances, Systems and Applications, 2(1), 9. https://doi.org/10.1186/2192113X-2-9

Hwang, M. I., \& Thorn, R. G. (1999). The Effect of User Engagement on System Success: A Meta-Analytical Integration of Research Findings. Information \& Management, 35(4), 229 236. https://doi.org/10.1016/S0378-7206(98)00092-5

Johnson, R. B., \& Onwuegbuzie, A. J. (2004). Mixed Methods Research: A Research Paradigm Whose Time Has Come. Educational Researcher, 33(7), 14-26. https://doi.org/url\{10.3102/0013189X033007014\}

Joint, A. and, \& Baker, E. (2011). Knowing the past to understand the present 1 - issues in the contracting for cloud based services. Computer Law \& Security Review, 27(4), 407-415. https://doi.org/10.1016/j.clsr.2011.05.002

Jones, S. (2015). Cloud computing procurement and implementation: Lessons learnt from a United Kingdom case study. International Journal of Information Management, 35(6), $712-$ 716. https://doi.org/10.1016/j.ijinfomgt.2015.07.007

Khorshed, M. T., Ali, A. B. M. S., \& Wasimi, S. A. (2012). A survey on gaps, threat remediation challenges and some thoughts for proactive attack detection in cloud computing. Future Generation Computer Systems, 28(6), 833-851. https://doi.org/10.1016/j.future.2012.01.006

King, W. R., \& He, J. (2006). A meta-analysis of the technology acceptance model. Information and Management, 43(6), 740-755. https://doi.org/10.1016/j.im.2006.05.003 
Kung, L., Cegielski, C. G., \& Kung, H. J. (2015). An integrated environmental perspective on software as a service adoption in manufacturing and retail firms. Journal of Information Technology, 30(4), 352-363. https://doi.org/10.1057/jit.2015.14

Laatikainen, G., Mazhelis, O., \& Tyrväinen, P. (2014). Role of acquisition intervals in private and public cloud storage costs. Decision Support Systems, 57(1), 320-330. https://doi.org/10.1016/j.dss.2013.09.020

Lai, I. K. W., Tam, S. K. T., \& Chan, M. F. S. (2012). Knowledge cloud system for network collaboration: A case study in medical service industry in China. Expert Systems with Applications, 39(15), 12205-12212. https://doi.org/10.1016/j.eswa.2012.04.057

Le Roux, C. J. B., \& Evans, N. (2011). Can cloud computing bridge the digital divide in South African secondary education? Information Development, 27(2), 109-116. Journal Article.

Levy, Y., \& Ellis, T. J. (2006). A systems approach to conduct an effective literature review in support of information systems research. Informing Science Journal, 9, 181-212. https://doi.org/10.1049/cp.2009.0961

Lian, J. W. (2015). Critical factors for cloud based e-invoice service adoption in Taiwan: An empirical study. International Journal of Information Management, 35(1), 98-109. https://doi.org/10.1016/j.ijinfomgt.2014.10.005

Lian, J. W., Yen, D. C., \& Wang, Y. T. (2014). An exploratory study to understand the critical factors affecting the decision to adopt cloud computing in Taiwan hospital. International Journal of Information Management, 34(1), 28-36. https://doi.org/10.1016/j.ijinfomgt.2013.09.004

Low, C., Chen, Y., \& Wu, M. (2011). Understanding the determinants of cloud computing adoption. Industrial Management \& Data Systems, 111(7), 1006-1023. https://doi.org/10.1108/02635571111161262

Luo, J., Li, X., \& Chen, M. (2014). Hybrid shuffled frog leaping algorithm for energy-efficient dynamic consolidation of virtual machines in cloud data centers. Expert Systems with Applications, 41(13), 5804-5816. https://doi.org/http://dx.doi.org/10.1016/j.eswa.2014.03.039

Makena, J. N. (2013). Factors That Affect Cloud Computing Adoption By Small And Medium Enterprises In Kenya. International Journal of Computer Applications Technology and Research, 2(5), 517. Journal Article.

Marston, S., Li, Z., Bandyopadhyay, S., Zhang, J., \& Ghalsasi, A. (2011). Cloud computing The business perspective. Decision Support Systems, 51(1), 176-189. https://doi.org/10.1016/j.dss.2010.12.006

Mateescu, G., Gentzsch, W., \& Ribbens, C. J. (2011). Hybrid Computing-Where HPC meets grid and Cloud Computing. Future Generation Computer Systems, 27(5), 440-453. https://doi.org/10.1016/j.future.2010.11.003

Mauch, V., Kunze, M., \& Hillenbrand, M. (2013). High performance cloud computing. Future Generation Computer Systems, 29(6), 1408-1416.

https://doi.org/10.1016/j.future.2012.03.011

Mell, P., \& Grance, T. (2011). The NIST Definition of Cloud Computing.

Mital, M., Pani, A. K., Damodaran, S., \& Ramesh, R. (2015). Cloud based management and control system for smart communities: A practical case study. Computers in Industry, 74, 162-172. https://doi.org/10.1016/j.compind.2015.06.009

Mouratidis, H., Islam, S., Kalloniatis, C., \& Gritzalis, S. (2013). A framework to support selection of cloud providers based on security and privacy requirements. Journal of Systems and Software, 86(9), 2276-2293. https://doi.org/10.1016/j.jss.2013.03.011 
Mtebe, J. S., \& Raisamo, R. (2014). eLearning Cost Analysis of On-Premise versus Cloudhosted Implementation in Sub-Saharan Countries. The African Journal of Information Systems, 6(2), 48-64.

Navimipour, N. J. (2015). A formal approach for the specification and verification of a Trustworthy Human Resource Discovery mechanism in the Expert Cloud. Expert Systems with Applications, 42(15-16), 6112-6131. https://doi.org/10.1016/j.eswa.2015.03.035

Ngai, E. W. T., \& Wat, F. K. T. (2002). A literature review and classification of electronic commerce research. Information \& Management, 39(5), 415-429. https://doi.org/10.1016/S0378-7206(01)00107-0

Nkhoma, M., \& Dang, D. (2013). Contributing factors of cloud computing adoption: a technology-organisation-environment framework approach. International Journal of Information Systems and Engineering, 1(1), 38-49.

Oliveira, T., Thomas, M., \& Espadanal, M. (2014). Assessing the determinants of cloud computing adoption: An analysis of the manufacturing and services sectors. Information and Management, 51(5), 497-510. https://doi.org/10.1016/j.im.2014.03.006

Pandey, S., Voorsluys, W., Niu, S., Khandoker, A., \& Buyya, R. (2012). An autonomic cloud environment for hosting ECG data analysis services. Future Generation Computer Systems, 28(1), 147-154. https://doi.org/10.1016/j.future.2011.04.022

Park, S. C., \& Ryoo, S. Y. (2013). An empirical investigation of end-users' switching toward cloud computing: A two factor theory perspective. Computers in Human Behavior, 29(1), 160-170. https://doi.org/10.1016/j.chb.2012.07.032

Petter, S., \& McLean, E. R. (2009). A meta-analytic assessment of the DeLone and McLean IS success model: An examination of IS success at the individual level. Information and Management, 46(3), 159-166. https://doi.org/10.1016/j.im.2008.12.006

Pi, E., Lu, H., Jiang, B., Huang, J., Peng, Q., \& Lin, X. (2011). Precise plant classification within genus level based on simulated annealing aided cloud classifier. Expert Systems with Applications, 38(4), 3009-3014. https://doi.org/10.1016/j.eswa.2010.08.090

Rasheed, H. (2014). Data and infrastructure security auditing in cloud computing environments. International Journal of Information Management, 34(3), 364-368. https://doi.org/10.1016/j.ijinfomgt.2013.11.002

Ratten, V. (2014). Indian and US consumer purchase intentions of cloud computing services. Journal of Indian Business Research, 6(2), 170-188. https://doi.org/10.1108/JIBR-07-20130068

Ratten, V. (2015). Factors influencing consumer purchase intention of cloud computing in the United States and Turkey. EuroMed Journal of Business, 10(1), 80-97. https://doi.org/10.1108/EMJB-02-2014-0007

Rezaei, R., Chiew, T. K., Lee, S. P., \& Shams Aliee, Z. (2014). A semantic interoperability framework for software as a service systems in cloud computing environments. Expert Systems with Applications, 41(13), 5751-5770. https://doi.org/10.1016/j.eswa.2014.03.020

Ryan, P., \& Falvey, S. (2012). Trust in the clouds. Computer Law and Security Review, 28(5), 513-521. https://doi.org/10.1016/j.clsr.2012.07.002

Safari, F., Safari, N., \& Hasanzadeh, A. (2015). The Adoption of SaaS: Ranking the Determinants. Journal of Enterprise Information Management, 28(3), 400-422. https://doi.org/10.1108/JEIM-02-2014-0017

Senyo, P. K., Effah, J., \& Addae, E. (2016). Preliminary insight into cloud computing adoption in a developing country. Journal of Enterprise Information Management, 29(4), 505-524. https://doi.org/http://dx.doi.org/10.1108/09564230910978511 
Sithole, E., McConnell, A., McClean, S., Parr, G., Scotney, B., Moore, A., \& Bustard, D. (2013). Cache Performance Models for Quality of Service Compliance in Storage Clouds. Journal of Cloud Computing: Advances, Systems and Applications, 2(1), 1-32. https://doi.org/10.1186/2192-113X-2-1

Son, I., Lee, D., Lee, J. N., \& Chang, Y. B. (2014). Market perception on cloud computing initiatives in organizations: An extended resource-based view. Information and Management, 51(6), 653-669. https://doi.org/10.1016/j.im.2014.05.006

Sultan, N. (2010). Cloud computing for education: A new dawn? International Journal of Information Management, 30(2), 109-116. https://doi.org/10.1016/j.ijinfomgt.2009.09.004

Sultan, N. (2013). Cloud computing: A democratizing force? International Journal of Information Management, 33(5), 810-815. https://doi.org/10.1016/j.ijinfomgt.2013.05.010

Sultan, N. (2014). Making use of cloud computing for healthcare provision: Opportunities and challenges. International Journal of Information Management, 34(2), 177-184. https://doi.org/10.1016/j.ijinfomgt.2013.12.011

Svantesson, D. J. B. (2012). Data protection in cloud computing - The Swedish perspective. Computer Law \& Security Review, 28(4), 476-480. https://doi.org/10.1016/j.clsr.2012.05.005

Thilakanathan, D., Chen, S., Nepal, S., Calvo, R., \& Alem, L. (2014). A platform for secure monitoring and sharing of generic health data in the Cloud. Future Generation Computer Systems, 35, 102-113. https://doi.org/10.1016/j.future.2013.09.011

Varadi, S., Kertesz, A., \& Parkin, M. (2012). The necessity of legally compliant data management in European cloud architectures. Computer Law and Security Review, 28(5), 577-586. https://doi.org/10.1016/j.clsr.2012.05.006

Venters, W., \& Whitley, E. A. (2012). A critical review of cloud computing: researching desires and realities. Journal of Information Technology, 27(3), 179-197. Journal Article.

Walterbusch, M., Martens, B., \& Teuteberg, F. (2013). Evaluating cloud computing services from a total cost of ownership perspective. Management Research Review, 36(6), 613-638. https://doi.org/10.1108/01409171311325769

Wang, N., Liang, H., Jia, Y., Ge, S., Xue, Y., \& Wang, Z. (2016). Cloud computing research in the IS discipline: A citation/co-citation analysis. Decision Support Systems, 86, 35-47. https://doi.org/10.1016/j.dss.2016.03.006

Wei, L., Zhu, H., Cao, Z., Dong, X., Jia, W., Chen, Y., \& Vasilakos, A. V. (2014). Security and privacy for storage and computation in cloud computing. Information Sciences, 258, 371386. https://doi.org/10.1016/j.ins.2013.04.028

Wu, W.-W. (2011). Mining significant factors affecting the adoption of SaaS using the rough set approach. Journal of Systems and Software, 84(3), 435-441. https://doi.org/10.1016/j.jss.2010.11.890

Yang, H., \& Tate, M. (2012). A Descriptive Literature Review and Classification of Cloud Computing Research. Communications of the Association of Information Systems, 31, 3560. https://doi.org/10.1.1.261.3070

Yeo, C. S., Venugopal, S., Chu, X., \& Buyya, R. (2010). Autonomic metered pricing for a utility computing service. Future Generation Computer Systems, 26(8), 1368-1380. https://doi.org/10.1016/j.future.2009.05.024

Yigitbasioglu, O. M. (2015). External auditors' perceptions of cloud computing adoption in Australia. International Journal of Accounting Information Systems, 18, 46-62. https://doi.org/10.1016/j.accinf.2015.09.001

Yu, Y., Niu, L., Yang, G., Mu, Y., \& Susilo, W. (2014). On the security of auditing mechanisms 
for secure cloud storage. Future Generation Computer Systems, 30(1), 127-132.

https://doi.org/10.1016/j.future.2013.05.005

Zhang, Y., Li, Y., \& Zheng, W. (2013). Automatic software deployment using user-level virtualization for cloud-computing. Future Generation Computer Systems, 29(1), 323-329. https://doi.org/10.1016/j.future.2011.08.012

Zissis, D., \& Lekkas, D. (2012). Addressing cloud computing security issues. Future Generation Computer Systems, 28(3), 583-592. https://doi.org/10.1016/j.future.2010.12.006 
APPENDIX 1

Distribution of articles by journal of publication

Journals

$\begin{array}{lllllllll}2009 & 2010 & 2011 & 2012 & 2013 & 2014 & 2015 & \text { Totals } & \text { Percentage }\end{array}$

Journal of Cloud Computing: Advances, Systems and

Applications

Future Generation Computer Systems

International Journal of Information Management

Computer Law \& Security Review

Expert Systems with Applications

Information Sciences

Information Systems

Decision Support Systems

Business \& Information Systems Engineering

Journal of Enterprise Information Management

Computers in Industry

Procedia Technology

European Journal of Information Systems

International Journal of Accounting Information Systems

Advances in Engineering Software

Communications of the Association for Information Systems

Computer Standards \& Interfaces

Electronic Commerce Research and Applications

International Journal of Cloud Computing and Services

Science

Journal of Information Technology

Journal of Management Information Systems

Journal of Network and Computer Applications

Journal of Systems and Information Technology

The Electronic Journal on Information Systems in Developing

Countries

\begin{tabular}{|c|c|c|c|c|c|c|c|c|}
\hline & & & 19 & 21 & 23 & 24 & 87 & $31 \%$ \\
\hline 1 & 4 & 4 & 6 & 12 & 6 & & 33 & $12 \%$ \\
\hline & 1 & 2 & 1 & 6 & 5 & 6 & 21 & $7 \%$ \\
\hline 1 & 2 & 3 & 7 & 4 & 1 & & 18 & $6 \%$ \\
\hline 1 & & 2 & 2 & & 5 & 2 & 12 & $4 \%$ \\
\hline & & & & & 5 & 3 & 8 & $3 \%$ \\
\hline & & & & 1 & & 7 & 8 & $3 \%$ \\
\hline 1 & & 2 & & 2 & 2 & 1 & 8 & $3 \%$ \\
\hline 1 & & 3 & & 2 & & & 6 & $2 \%$ \\
\hline & & & & 1 & & 5 & 6 & $2 \%$ \\
\hline & & & & & 3 & 1 & 4 & $1 \%$ \\
\hline & & & 3 & & 1 & & 4 & $1 \%$ \\
\hline & & & & 1 & 2 & & 3 & $1 \%$ \\
\hline & & & & & & 3 & 3 & $1 \%$ \\
\hline & & & & 1 & 1 & & 2 & $1 \%$ \\
\hline & 1 & & 1 & & & & 2 & $1 \%$ \\
\hline & & & & & & 2 & 2 & $1 \%$ \\
\hline & & & & & & 2 & 2 & $1 \%$ \\
\hline & & & & 2 & & & 2 & $1 \%$ \\
\hline & & & 1 & & & 1 & 2 & $1 \%$ \\
\hline & 1 & & & 1 & & & 2 & $1 \%$ \\
\hline & & & & & 1 & 1 & 2 & $1 \%$ \\
\hline & & & & & 1 & 1 & 2 & $1 \%$ \\
\hline & & & & 1 & 1 & & 2 & $1 \%$ \\
\hline
\end{tabular}




\begin{tabular}{|c|c|c|c|c|c|c|c|c|c|}
\hline The Electronic Library & & & 1 & & 1 & & & 2 & $1 \%$ \\
\hline ACM Computer Communication Review & 1 & & & & & & & 1 & $0 \%$ \\
\hline Aslib Proceedings: New Information Perspective & & & & & 1 & & & 1 & $0 \%$ \\
\hline Behaviour \& Information Technology & & & 1 & & & & & 1 & $0 \%$ \\
\hline Campus Wide Information Systems & & & & & & 1 & & 1 & $0 \%$ \\
\hline Computer Networks & & & & & & 1 & & 1 & $0 \%$ \\
\hline Computers in Human Behavior & & & & & 1 & & & 1 & $0 \%$ \\
\hline EuroMed Journal of Business & & & & & & & 1 & 1 & $0 \%$ \\
\hline Global Journal of Business Research & & & & 1 & & & & 1 & $0 \%$ \\
\hline Industrial Management \& Data Systems & & & 1 & & & & & 1 & $0 \%$ \\
\hline Info & & & & & & & 1 & 1 & $0 \%$ \\
\hline Information and Management & & & & & & 1 & & 1 & $0 \%$ \\
\hline Information Development & & & 1 & & & & & 1 & $0 \%$ \\
\hline $\begin{array}{l}\text { International Journal of Computer Applications Technology } \\
\text { and Research }\end{array}$ & & & & & 1 & & & 1 & $0 \%$ \\
\hline International Journal of Computer Science Issues & & & 1 & & & & & 1 & $0 \%$ \\
\hline International Journal of Emerging Science and Engineering & & & & & & 1 & & 1 & $0 \%$ \\
\hline International Journal of Information Systems \& Engineering & & & & & 1 & & & 1 & $0 \%$ \\
\hline International Journal of Logistics Management & & & & & & & 1 & 1 & $0 \%$ \\
\hline International Journal of Trade, Economics and Finance & & & & & & 1 & & 1 & $0 \%$ \\
\hline Journal of Computing & & 1 & & & & & & 1 & $0 \%$ \\
\hline Journal of Computing \& Organizational Dynamics & & & & & 1 & & & 1 & $0 \%$ \\
\hline Journal of Engineering and Technology Management & & & & & & 1 & & 1 & $0 \%$ \\
\hline Journal of Financial Crime & & & & & 1 & & & 1 & $0 \%$ \\
\hline Journal of Grid Computing & & & & & 1 & & & 1 & $0 \%$ \\
\hline Journal of High Technology Management Research & & & & 1 & & & & 1 & $0 \%$ \\
\hline Journal of Indian Business Research & & & & & & 1 & & 1 & $0 \%$ \\
\hline Journal of Information Systems Research and Innovation & & & & & 1 & & & 1 & $0 \%$ \\
\hline Journal of Information Technology Management & & & 1 & & & & & 1 & $0 \%$ \\
\hline
\end{tabular}




\begin{tabular}{|c|c|c|c|c|c|c|c|c|c|}
\hline Journal of Information Technology Theory and Application & & & & 1 & & & & 1 & $0 \%$ \\
\hline $\begin{array}{l}\text { Journal of International Technology \& Information } \\
\text { Management }\end{array}$ & & & 1 & & & & & 1 & $0 \%$ \\
\hline Journal of Management Research & & & & & 1 & & & 1 & $0 \%$ \\
\hline Journal of Service Science & & 1 & & & & & & 1 & $0 \%$ \\
\hline Journal of Strategic Information Systems & & & & & & & 1 & 1 & $0 \%$ \\
\hline Journal of Technology Management for Growing Economies & & & 1 & & & & & 1 & $0 \%$ \\
\hline Management Research Review & & & & & 1 & & & 1 & $0 \%$ \\
\hline Mathematical and Computer Modelling & & & 1 & & & & & 1 & $0 \%$ \\
\hline Procedia Economics and Finance & & & & 1 & & & & 1 & $0 \%$ \\
\hline Procedia Social and Behavioral Sciences & & 1 & & & & & & 1 & $0 \%$ \\
\hline South African Journal of Business Management & & & & 1 & & & & 1 & $0 \%$ \\
\hline Telecommunications Policy & & & & & 1 & & & 1 & $0 \%$ \\
\hline The African Journal of Information Systems & & & & & & 1 & & 1 & $0 \%$ \\
\hline The International Journal of Logistics Management & & & & 1 & & & & 1 & $0 \%$ \\
\hline The Journal of Systems \& Software & & & 1 & & & & & 1 & $0 \%$ \\
\hline Totals & 6 & 12 & 26 & 46 & 67 & 65 & 63 & 285 & $100 \%$ \\
\hline
\end{tabular}




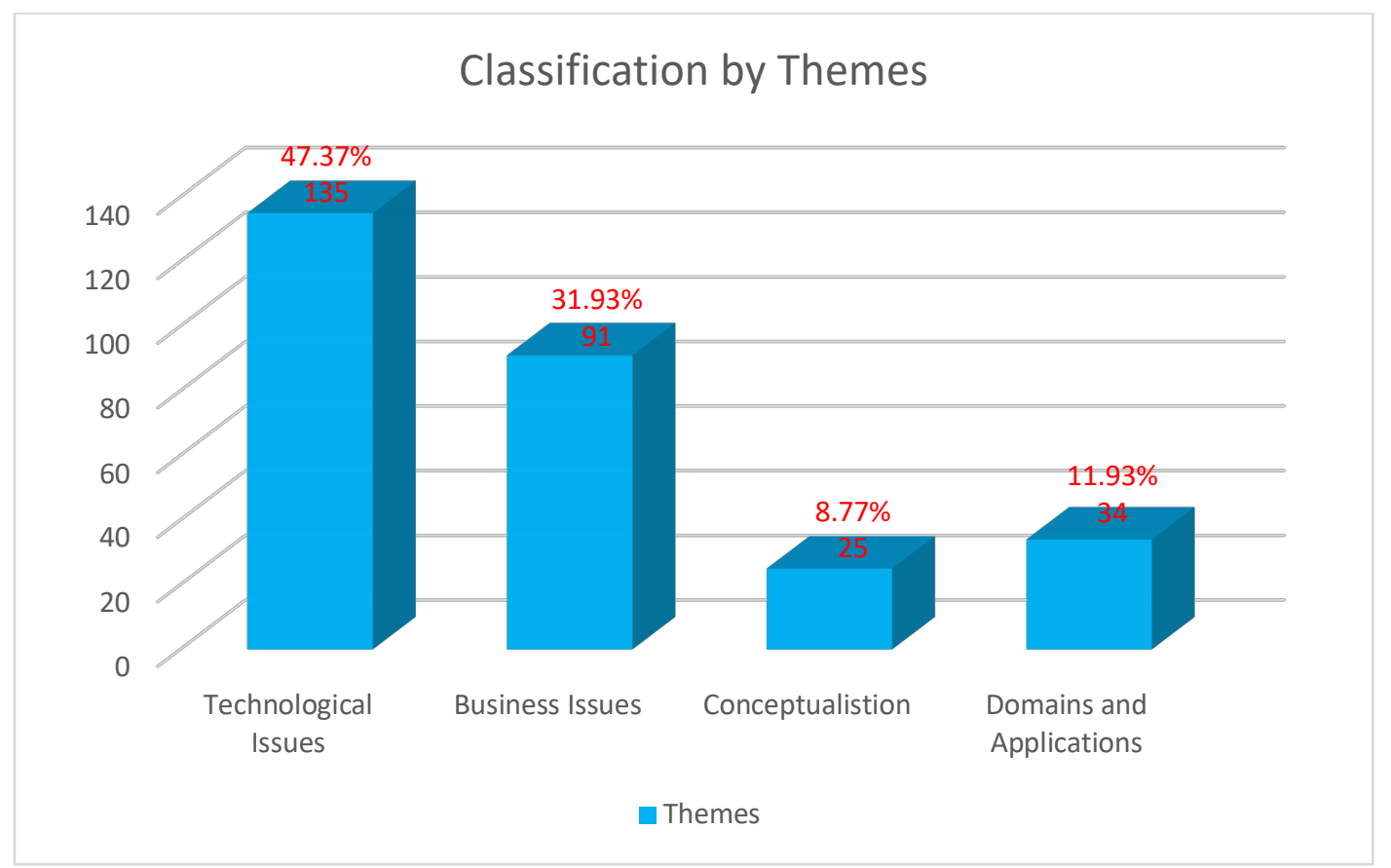

Figure 1: Literature classification by research themes 


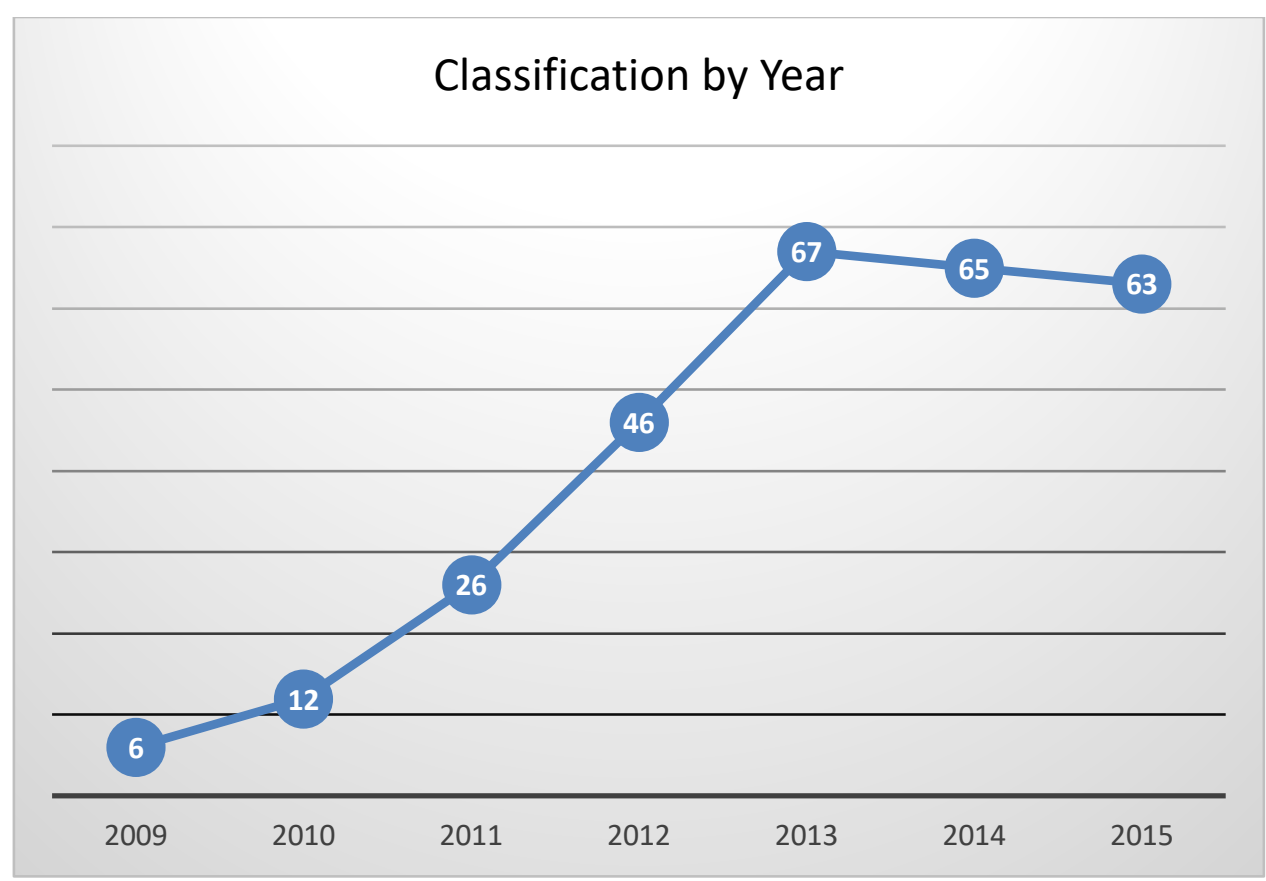

Figure 2: Literature classification by year of publication 


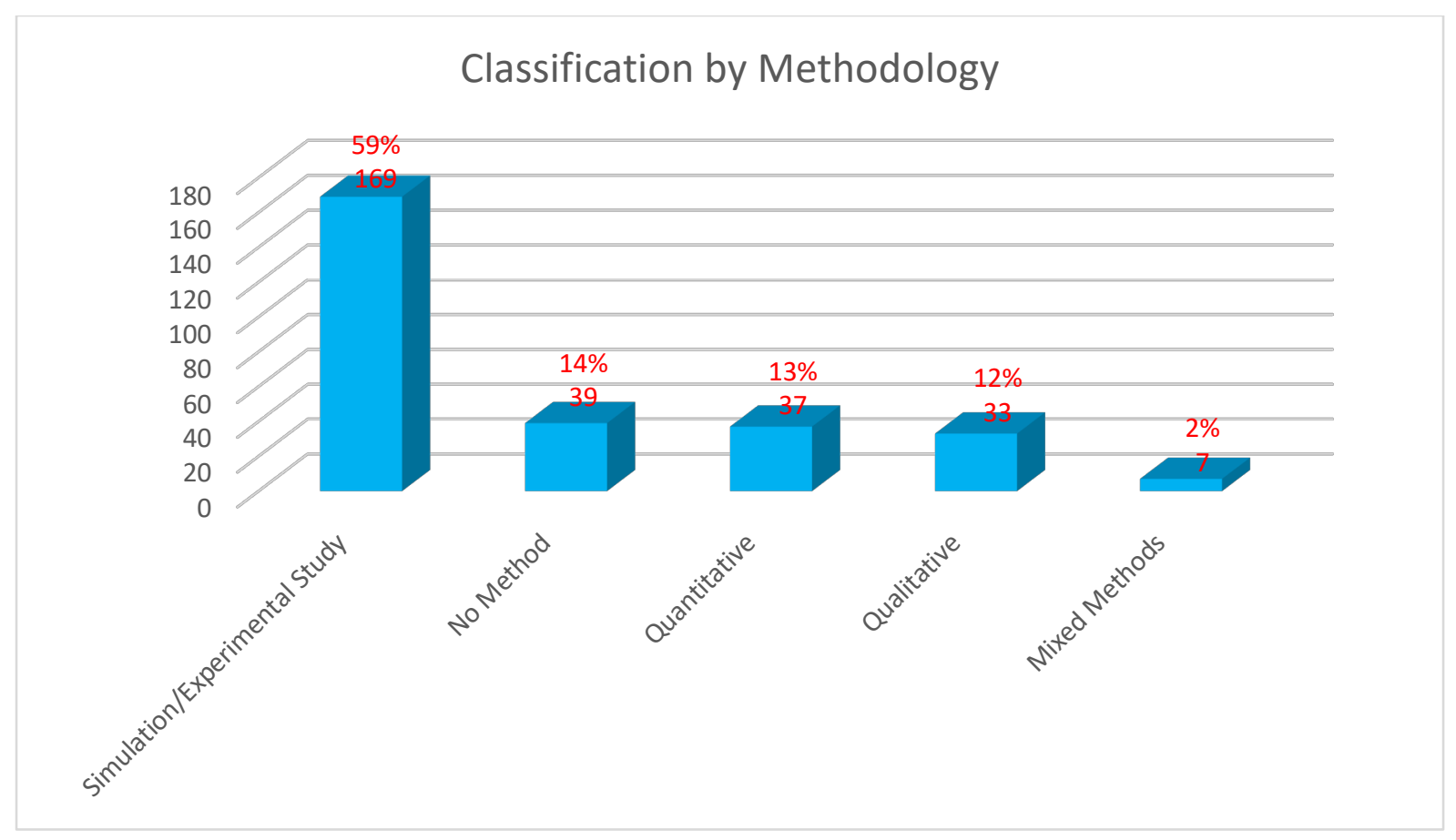

Figure 3: Literature classification by research methodology 


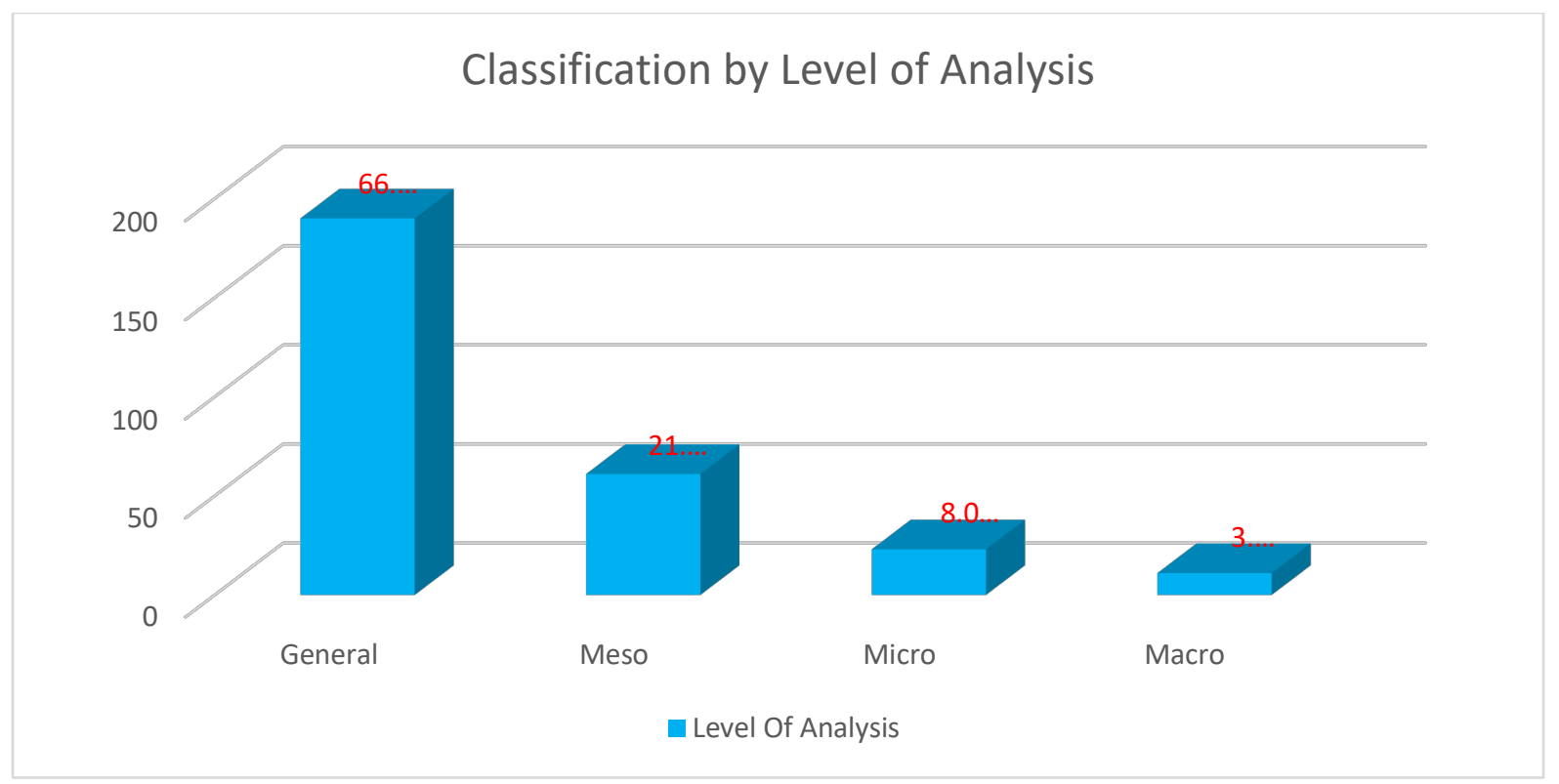

Figure 4: Literature classification by level of analysis 


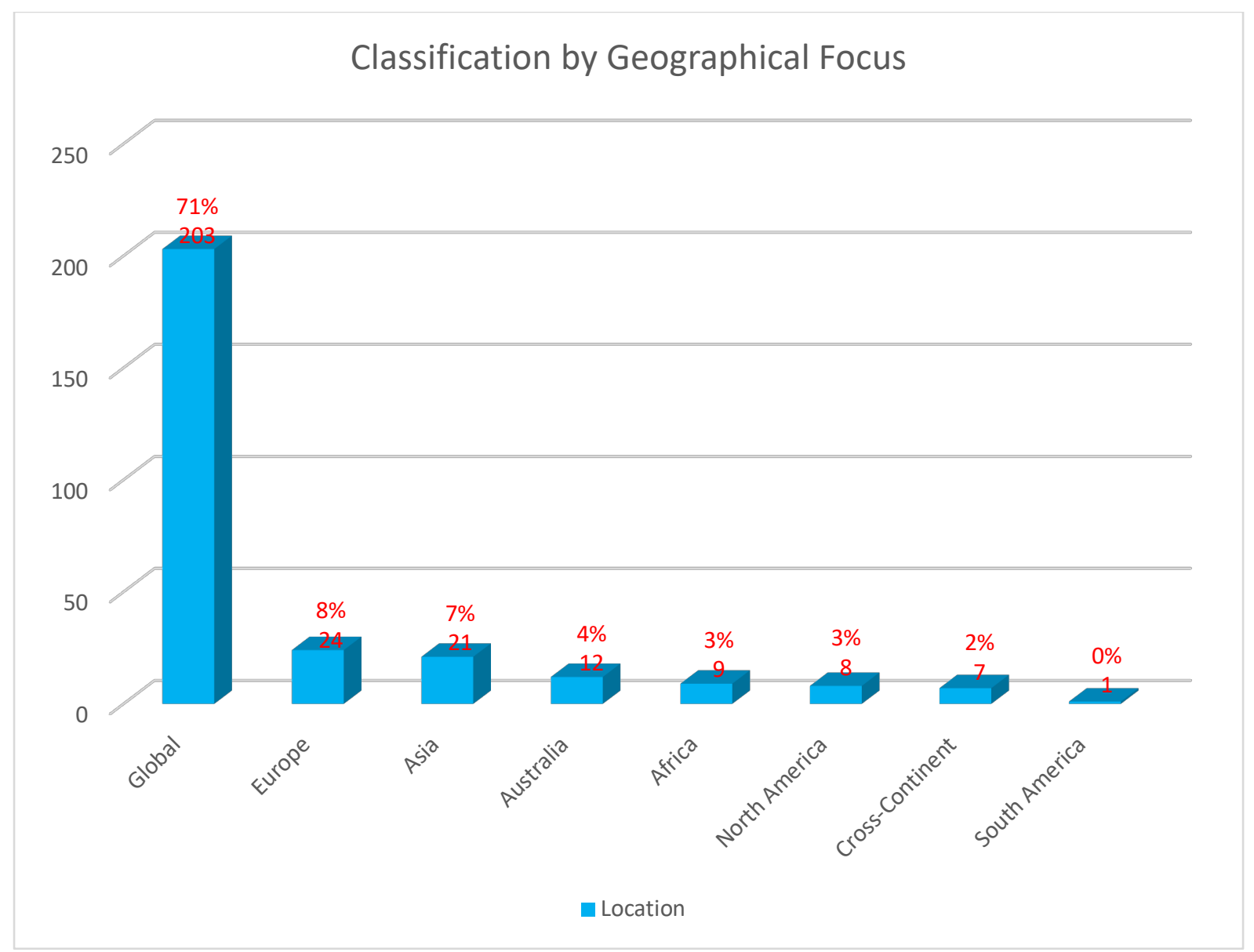

Figure 5: Literature Classification by Location 
Table 1 Cloud computing literature classification framework (Adapted from Yang and Tate (2012)

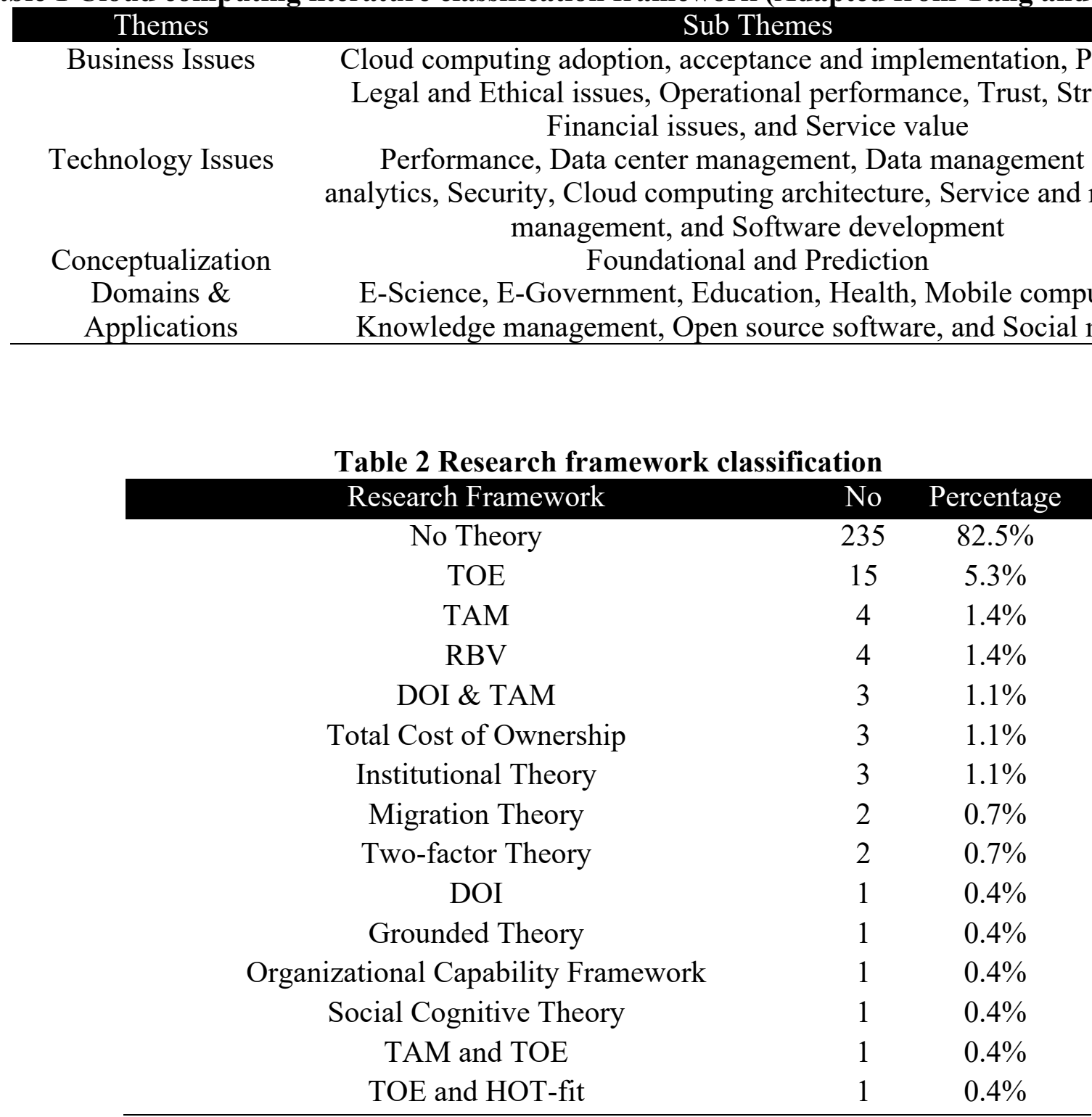




\begin{tabular}{ccc}
\hline TOE and DOI & 1 & $0.4 \%$ \\
TAM and Social Cognitive Theory & 1 & $0.4 \%$ \\
TRA & 1 & $0.4 \%$ \\
TRA \& TAM & 1 & $0.4 \%$ \\
Triple T & 1 & $0.4 \%$ \\
Expectation Confirmation Model & 1 & $0.4 \%$ \\
Dual Inheritance Theory & 1 & $0.4 \%$ \\
Unified Theory of Acceptance and Use of Technology & 1 & $0.4 \%$ \\
& 285 & $100.0 \%$ \\
\hline
\end{tabular}

Table 3 Research frameworks and levels of application in literature

\section{Research Frameworks}

Diffusion of Innovation

Technology Adoption Model

Grounded Theory

Theory of Reasoned Action

Technology Organization and Environment framework

Two-Factor Theory

Total Cost of Ownership

Migration Theory

Resource Based View

Social Cognitive Theory

\section{Application}

Level

Meso

Micro

Meso

Micro

Meso

Micro

Meso

Micro

Meso

Micro
Source

(Kung, Cegielski, \& Kung, 2015;

Oliveira et al., 2014;

Yigitbasioglu, 2015)

(Gottschalk \& Kirn, 2013; Ratten, 2015; Wu, 2011)

(Dahiru et al., 2014)

(Benlian \& Hess, 2011)

(Hsu et al., 2014; Lian, 2015; Lian et al., 2014; Low et al., 2011)

(Park \& Ryoo, 2013))

(Mtebe \& Raisamo, 2014;

Walterbusch et al., 2013)

(Bhattacherjee \& Park, 2014)

(Son et al., 2014)

(Ratten, 2014, 2015) 
